\title{
A INSTITUCIONALIZAÇÃO DA ENFERMAGEM PEDIÁTRICA: OS CURSOS DAS ESCOLAS PÚBLICAS DO RIO DE J ANEIRO (1986-1999)
}

\author{
The Institutionalization of the Pediatric Nursing: \\ the Courses of the Public Schools of Rio de J aneiro (1986 - 1999) \\ La Institucionalización de la Enfermería Pediátrica: \\ los Cursos de las Escuelas Publicas del Rio de J aneiro (1986 -1999)
}

Jakcilane Rosendo de Góis

Suzy Groeger Lapa

\author{
Priscila dos Anjos Fonseca \\ Isabel Cristina dos Santos Oliveira
}

\begin{abstract}
Resumo
Trata-se de um estudo na perspectiva histórica, tendo como objetivo caracterizar os cursos de especialização em enfermagem pediátrica e neonatal das escolas de enfermagem públicas do Estado do Rio de Janeiro (1986 a 1999). As fontes primárias escritas são os relatórios e a legislação dos cursos existentes nos departamentos das escolas de enfermagem e nos acervos históricos das universidades. Em 1986, foram criados 2 cursos de especialização em enfermagem pediátrica (EEAN/UFRJ e EEAAC/UFF) e em 1992, um curso de especialização em enfermagem neonatal (FENF/UERJ). Constatou-se que os referidos cursos eram diferentes entre si, já que o da EEAN/UFRJ e FENF/UERJ enfocavam, em destaque, a criança no cenário hospitalar, e o da EEAAC/UFF abordava, também, a criança na comunidade. Conclui-se que a criação e a implementação dos três cursos demarcam a institucionalização da especialidade - enfermagem pediátrica no Estado do Rio de Janeiro.
\end{abstract}

Palavras-chave: Enfermagem. Pediatria. Especialização. História da Enfermagem.

\section{Abstract}

It is a study in the historical perspective, having as objective to characterize the specialization courses in pediatric and neonatal nursing of the public schools from Rio de Janeiro State (1986 trough 1999). The primary written sources are the reports and the course's legislation existents in the departments of the nursing schools and the historical archive of the universities. In 1986, were created 2 courses of specialization in pediatric nursing (EEAN/UFRJ e EEAAC/UFF) and in 1992, a specialization course in neonatal nursing (FENF/UERJ). It was noticed that the mentioned courses were different among them, while the course from EEAN/UFRJ and FENF/UERJ focused, in detach, the child in the hospital scenery, and the one from EAAC/UFF approached, also, the child in the community. It was conclude that the creation and the implementation of the three courses demarcated the institutionalization of the specialty - pediatric nursing in the Rio de Janeiro State.

Keywords:

Nursing. Pediatrics. Specialism. History of Nursing.

\section{Resumen}

Se trata de un estudio en la perspectiva histórica, teniendo como objetivo caracterizar los cursos de especialización en enfermería pediátrica y neonatal de las escuelas de enfermería públicas del Estado del Rio de Janeiro (1986 a 1999). La fuentes primarias escritas son los relatos y la legislación de los cursos existentes en los departamentos de las escuelas de enfermería y en los archivos históricos de las universidades. En 1986, fueran creados 2 cursos de especialización en enfermería pediátrica (EEAN/UFRJ y EEAAC) UFF) y en 1992, un curso de especialización en enfermería neonatal (FENF/UERJ). Fue constatado que los referidos cursos eran diferentes entre si, ya que el de la EEAN/UFRJ y FENF/UERJ enfocaban, en destaque, el niño en el escenario hospitalario, y el de la EEAAC/UFF abordaba, también, el niño en la comunidad. Fue concluido que la creación y la implementación de los tres cursos demarcan la institucionalización de la especialidad - enfermería pediátrica en el Estado del Rio de Janeiro.

Palabras clave:

Enfermería. Pediatría. Especialización. Historia de la Enfermería. 


\section{INTRODUÇÃO}

Entre as décadas de 1930 e 1950, foram criados vários hospitais especializados no atendimento à criança. Segundo Oliveira" (1996, p. 158): “... existia um déficit quantitativo e qualitativo de enfermeiras para atender ao novo mercado de trabalho. Com isso, era necessária a criação de escolas de enfermagem, como também a capacitação de profissionais...".

Na década de 1970, inicia-se a criação dos cursos de especialização em Enfermagem Pediátrica para atender a demanda e a necessidade de capacitação das enfermeiras. Com isto, foi criado, no país, o primeiro curso de especialização em Pediatria e Puericultura na Escola Paulista de Enfermagem, atual Departamento de Enfermagem da Universidade Federal de São Paulo - UNIFESP?2.

0 referido curso foi criado, em 1972, com a finalidade de complementar a assistência materno-infantil e seguia os padrões estabelecidos pela Escola de Puericultura da Faculdade de Medicina da Universidade de Paris ${ }^{3}$. Segundo Barbosa ${ }^{3: 33}$

O CEPP era composto por uma vasta grade curricular básica, que culminava em três áreas específicas de Enfermagem, ou seja, a Pediatria Médica e Cirúrgica, a Pediatria Social e a Neonatologia. A ênfase maior desse conteúdo exprimia a nossa principal preocupação que era direcionada para a criança na comunidade e nas instituições, e em segundo plano a criança hospitalizada.

Desta forma, este estudo está inserido no Projeto Integrado de Pesquisa/CNPq intitulado: A Institucionalização da Enfermagem Pediátrica: a influência da especialização na prática profissional nos anos 1970, tendo como objetivo caracterizar os cursos de especialização em Enfermagem Pediátrica e Neonatal das escolas de enfermagem públicas do Estado do Rio de Janeiro, no período de 1986 a 1999.

No Estado do Rio de Janeiro existem quatro escolas de enfermagem públicas, porém três desenvolveram cursos de especialização no período estudado a saber: Escola de Enfermagem Anna Nery da Universidade Federal do Rio de Janeiro (EEAN/UFRJ); Escola de Enfermagem Aurora Afonso Costa da Universidade Federal Fluminense (EEAAC/UFF); e Faculdade de Enfermagem da Universidade do Estado do Rio de Janeiro (FENF/UERJ). Foi solicitada permissão para a utilização dos nomes das instituições.

0 recorte se justifica em 1986 pela criação dos cursos de especialização em Enfermagem Pediátrica da EEAN/UFRJ e da EEAAC/UFF, e em 1999, quando ocorreu a reformulação do Curso de Especialização em Enfermagem Neonatal da FENF/UERJ.

Trata-se de um estudo na perspectiva histórica. Segundo Vieira et al. ${ }^{4: 11}$ :

... fazer história como conhecimento e como vivência é recuperar a ação de diferentes grupos que nela atuam, procurando entender por que o processo tomou um dado rumo, e não outro. Significa resgatar as injunções que permitiram a concretização de uma possibilidade, e não de outras.

As fontes primárias escritas são os relatórios contendo dados sobre as disciplinas ministradas, atividades desenvolvidas, carga horária, número de créditos, corpo docente e sua titulação, e corpo discente, bem como a legislação pertinente dos cursos de especialização em Enfermagem Pediátrica e Neonatal existentes nos Departamentos de Enfermagem Materno-Infantil da EEAN/UFRJ e EEAAC/UFF; no Centro de Memória da FENF/UERJ; na Divisão de Comunicações/UFRJ e Centro de Ciências Médicas /UFF.

0 levantamento das fontes primárias escritas foi, algumas vezes, prejudicado pelo fato de os documentos estarem dispersos e, ainda, alguns destes terem sido descartados.

As fontes secundárias referem-se aos livros de Enfermagem, História do Brasil e Legislação, além de artigos de Enfermagem publicados em periódicos nacionais.

0 método utilizado para analisar os dados foi a análise documental, que segundo Caulley apud Lüdke \& Andrée 538

... busca identificar informações factuais nos documentos a partir de questões ou hipóteses de interesse.

\section{CURSOS DE ESPECIALIZAÇÃO NO PAÍS: ASPECTOS LEGAIS}

Nos anos de 1970, o Conselho Federal de Enfermagem (COFEn) através da Lei $n^{\circ}$ 5905, de 12 de julho de 1973, estabeleceu que serão qualificados como especialistas os enfermeiros providos de conhecimentos científicos e proficiência técnica nos setores a saber: Enfermagem Obstétrica, Enfermagem Pediátrica, Enfermagem Clínico-Cirúrgica, Enfermagem Geriátrica e Gerontológica, Enfermagem Psiquiátrica, Enfermagem de Saúde Pública, Enfermagem do Trabalho e Administração de Serviços de Enfermagem ${ }^{6}$.

Ainda, o COFEn estabelece que a especialização em Enfermagem Pediátrica qualifica o enfermeiro como especialista na assistência integral à criança, desde 0 nascimento até a adolescência, centrada na família e comunidade. Em referência à instituição promovedora do curso de pós-graduação, esta poderá somente ser considerada como formadora de especialistas, caso possua uma carga horária mínima de 800 horas $^{6}$.

Em 1977, o Conselho Federal de Educação (CFE), atualmente Câmara de Educação Superior, do Ministério da Educação, estabelece, através da Resolução n $14 / 77$, que os cursos de especialização se destinam a graduados e serão ministrados por instituições de ensino superior, que ofereçam curso de graduação reconhecido ou curso de pós-graduação credenciado; e exige que a qualificação mínima de todo o corpo docente seja o título de mestre obtido em instituição credenciada. Os docentes altamente qualificados, não portadores de titulação de mestre, poderão lecionar desde que a titulação seja julgada suficiente pelo referido conselho ${ }^{7}$.

Ainda, o CFE determina que os cursos devam ter carga horária mínima de 360 horas, da qual $4 / 5$ deverão ser dedicados ao conteúdo especifico dos cursos e ser ministrado no máximo por dois anos.

No âmbito estadual, em 1978, o Conselho de Ensino para Graduados (CPEG) da Universidade Federal do Rio de Janeiro estabelece a Resolução CPEG $n^{0} 78$ que regulamenta os cursos em nível de aperfeiçoamento, especialização, treinamento 
profissional e atualização. Esta resolução tem os critérios semelhantes a do $\mathrm{CFE}^{8}$.

Em 1983, o Ministério da Educação promulga a Resolução $12 / 83$, que substitui a citada anteriormente (14/77), fixando novas condições para a validade dos certificados dos cursos de aperfeiçoamento e especialização. Para uma instituição de ensino superior ministrar esses cursos, será necessário que ofereça cursos de graduação e/ou de pós-graduação na mesma área, por pelo menos cinco anos. Porém, outras instituições poderão, a critério do Conselho de Educação, ser autorizadas a oferecer os cursos.

0 critério para a titulação mínima do corpo docente é mantido, contudo o número de docentes sem título de mestre não poderá ultrapassar $1 / 3$ do corpo docente, salvo em casos excepcionais, previamente verificados pelo Conselho de Educação.

A carga horária mínima de 360 horas foi mantida, sendo que pelo menos 60 horas deverão ser utilizadas com disciplinas de formação didático-pedagógica e o restante, para o conteúdo específico, incluindo a iniciação à pesquisa.

Em 1986, ocorreu a criação do Curso de Especialização em Enfermagem Pediátrica da EEAAC/ UFF, conforme as exigências do CFE e da Resolução ${ }^{\circ}$ $25 / 81^{10}$ do Conselho de Pesquisa da UFF.

0 Regulamento do Curso de Especialização em Enfermagem Pediátrica fixava que o coordenador deve ser um professor com título de Mestre na área de Enfermagem Pediátrica e que caberá a este estabelecer o número de vagas anualmente. Além disso, o curso deve ter duração mínima de 1.100 horas. Os outros critérios são semelhantes aos do CFE.

Em 1989, com base na resolução do CEPG/UFRJ, a Coordenação dos Cursos de Pós-Graduação em Enfermagem (CCPGEn) da EEAN, através de seu regulamento, firmou que os cursos de especialização, incluindo o de Enfermagem Pediátrica, seriam administrados por comissão presidida por um coordenador adjunto, professor doutor, eleito pelos corpos docente e discente e submetido à apreciação do CCPGEn e homologação do CPEG. Além disso, os programas de pósgraduação lato sensu deverão ser propostos pelos departamentos da Escola, que indicarão o responsável acadêmico e seu suplente, aprovado pelo corpo deliberativo ${ }^{11}$.

Em 1991, o Conselho de Ensino e Pesquisa da UFF aprovou a nova estrutura do Curso de Especialização em Enfermagem Pediátrica através da Decisão no $153 / 91^{12}$.

No ano de 1992, o Conselho Superior de Ensino e Pesquisa, atual Conselho Superior de Ensino, Pesquisa e Extensão da UERJ, aprovou a Deliberação no 005/92, que autorizou a criação do Curso de Especialização em Enfermagem Neonatal da FENF/UERJ. Por meio desta, ficou determinado que o curso deveria ser integralizado em 825 horas, correspondentes a 33 créditos e distribuídas em disciplinas obrigatórias agrupadas em dois módulos, sendo o primeiro comum a todos os cursos de especialização da referida faculdade, e o segundo, específico do Curso de Especialização em Enfermagem Neonatal ${ }^{13}$.

Em 1997, o Curso de Especialização da FENF/UERJ sofre uma reestruturação autorizada pelo Conselho Superior de Ensino e Pesquisa, conforme consta na Deliberação $n^{0}$ 022/ 97. As principais mudanças ocorridas no curso foram quanto à carga horária que passa de 825 para 795 horas, ao número de créditos que passa de 33 para 35 e quanto ao número mínimo de alunos para funcionamento do curso, que passa de 4 para 6 , sendo 12 o máximo permitido ${ }^{14}$.

Em 1999, a Câmara de Educação Superior do Conselho Nacional de Educação promulga a Resolução CES n ${ }^{0} 3$, estabelecendo que os cursos de especialização somente poderão ser oferecidos por instituições de ensino de nível superior, que ministrem curso de graduação ou pós-graduação stricto-sensu reconhecido. Os cursos deverão ser ministrados num prazo mínimo de 6 meses $^{15}$.

0 Curso de Especialização em Enfermagem Neonatal, neste mesmo ano, passa por uma reformulação autorizada pelo Conselho Superior de Ensino, Pesquisa e Extensão de acordo com a deliberação $n^{0}$ 027/99. Os aspectos que diferem em relação à deliberação anterior são: carga horária total de 360 horas; número de créditos igual a 14; e 8 alunos, no mínimo, e 20, no máximo, para funcionamento do curso $^{16}$.

\section{ESPECIALIZAÇÃO EM ENFERMAGEM PEDIÁTRICA E NEONATAL: CARACTERÍSTICAS DOS CURSOS}

\section{Especialização em Enfermagem \\ Pediátrica: o caso da EEAN/ UFRJ}

0 primeiro projeto de criação de um curso na EEAN/UFRJ com o objetivo de ampliar os conhecimentos na área de Enfermagem Pediátrica foi em 1974, cuja modalidade era Curso de Extensão em Enfermagem Pediátrica, com carga horária total de 20 horas. Em 1983, o curso passou a chamar-se Curso de Aperfeiçoamento em Enfermagem Pediátrica, possuindo uma carga horária total de 365 horas.

0 período do governo do Presidente João Batista de Figueiredo (1979-1985) foi comprometido pela abertura do país, para que o mesmo se conduzisse ao estado de direito ${ }^{17}$. Em relação à saúde, em 1983, a Divisão Nacional MaternoInfantil (DINSAMI) criou o Programa de Assistência Integral da Mulher e da Criança (PAISMC). Em 1984, houve a separação do programa da mulher, vindo a ser denominado Programa de Assistência Integral à Saúde da Criança (PAISC) com o objetivo geral de criar condições para 0 atendimento integrado à saúde da criança de zero a cinco anos, visando à diminuição da mortalidade infantil ${ }^{18}$.

Em 1986, o referido curso sofreu nova modificação, denominando-se então Curso de Especialização em Enfermagem Pediátrica, com carga horária total de 560 horas e com os seguintes objetivos: oferecer aos enfermeiros oportunidades para identificar fatores de risco para a criança nos períodos pré, trans e pós-natal; avaliar o estado da saúde da criança nos diferentes estágios de seu desenvolvimento; utilizar métodos e técnicas assistenciais em enfermagem pediátrica e pré-natal; e aplicar metodologia de ensino e pesquisa adequada à resolução de problemas de saúde da criança, utilizando plenamente os recursos institucionais e familiares ${ }^{19}$.

Constata-se que os referidos cursos atendem os critérios das resoluções do CFE e CEPG/UFRJ no tocante à carga horária 
mínima de 360 horas, preconizada para os cursos de aperfeiçoamento e especialização. Quanto ao curso de extensão, a Resolução do CEPG/UFRJ ${ }^{20} \mathrm{~s} / \mathrm{n}$, de 1969, diz que estes cursos são abertos a candidatos, graduados ou não, que preencham as exigências estabelecidas, cabendo ao CEPG aprovar os cursos.

A resolução estabelece que esses cursos poderão ser ministrados em convênios da UFRJ com entidades públicas ou privadas, nacionais, internacionais ou estrangeiras. Além disso, poderão ser realizados em qualquer época do ano, sem prejuízo dos horários curriculares.

Pode-se supor que esta trajetória se explica pela tentativa de criação de um curso de especialização em Enfermagem Pediátrica na EEAN/UFRJ, desde meados da década de 1970.

Nos anos de 1988 e 1989, o curso permaneceu com a mesma denominação, modificando-se somente a carga horária total, que passou para 800 horas e 810 horas, respectivamente. Além das resoluções da UFRJ citadas anteriormente, este último seguiu também os critérios da Resolução do COFEn n 100/ $73^{6}$, já citada anteriormente. Vale destacar que não foram encontrados dados referentes ao ano de 1987.

A Tabela 1 apresenta a estrutura curricular com a denominação das disciplinas e distribuição das cargas horárias.

Tabela 1: Estrutura Curricular

\begin{tabular}{|c|c|c|c|c|c|}
\hline Ano & Disciplinas & 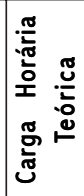 & 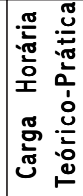 & 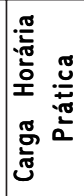 & 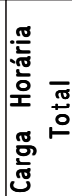 \\
\hline \multirow{4}{*}{1986} & $\begin{array}{l}\text { - Cuidados Básicos de } \\
\text { Enfermagem Pediátrica }\end{array}$ & 90 & 45 & 100 & 235 \\
\hline & $\begin{array}{l}\text { - A Enfermagem e } \\
\text { a Criança Doente }\end{array}$ & 90 & 45 & 100 & 235 \\
\hline & $\begin{array}{l}\text { - Metodologia do } \\
\text { Ensino Superior }\end{array}$ & 30 & 60 & - & 90 \\
\hline & Total & 210 & 450 & 200 & 560 \\
\hline \multirow{8}{*}{1989} & $\begin{array}{l}\text { - Cuidados Básicos } \\
\text { na Infância }\end{array}$ & 45 & 45 & 90 & 180 \\
\hline & $\begin{array}{l}\text { - Assistência ao } \\
\text { Recém-Nascido }\end{array}$ & 30 & - & 60 & 90 \\
\hline & $\begin{array}{l}\text {-Problemática } \\
\text { e Assistência } \\
\text { do Adolescente }\end{array}$ & 30 & - & 60 & 90 \\
\hline & $\begin{array}{l}\text { - A Enfermeira e } \\
\text { a Criança Enferma }\end{array}$ & 100 & - & 125 & 225 \\
\hline & $\begin{array}{l}\text { - Metodologia do } \\
\text { Ensino Superior }\end{array}$ & 45 & 45 & - & 90 \\
\hline & $\begin{array}{l}\text { - Relações Interpessoais } \\
\text { em Enfermagem }\end{array}$ & 15 & - & 30 & 45 \\
\hline & $\begin{array}{l}\text {-Metodologia } \\
\text { da Pesquisa }\end{array}$ & 45 & 45 & - & 90 \\
\hline & Total & 310 & 135 & 365 & 810 \\
\hline
\end{tabular}

Fonte: Relatórios dos Cursos de Especialização em Enfermagem Pediátrica dos anos de 1986 e 1989 (DEMI-EEAN/UFRJ).

Em 1988, as disciplinas Assistência ao Recém-nascido, Problemática e Assistência do Adolescente e Metodologia da Pesquisa foram incluídas na estrutura curricular. Cabe destacar que não foram encontrados dados referentes às subdivisões da carga horária total.

A inclusão da disciplina Problemática e Assistência do Adolescente vem ao encontro das políticas governamentais no setor saúde. Em 1989, foi criado o Programa Nacional de Saúde do Adolescente com o objetivo de promover a saúde integral do adolescente, favorecendo o seu crescimento e desenvolvimento, a redução da morbimortalidade ${ }^{21}$.

No ano de 1989, ocorreu a inclusão da disciplina Relações Interpessoais em Enfermagem. Essa disciplina, a Metodologia da Pesquisa e a Metodologia do Ensino foram exigidas como disciplinas obrigatórias conforme o capítulo IV do regulamento do CCPGEn da EEAN/UFRJ, no qual as disciplinas deverão ser comuns a todos os cursos em nível de especialização da referida escola.

De acordo com a denominação das disciplinas, verifica-se que, no período estudado, três disciplinas estão relacionadas à assistência intra-hospitalar, e uma disciplina refere-se à assistência extra-hospitalar, bem como há uma disciplina para cada temática: ensino, pesquisa e relação interpessoal.

Os cenários de prática do curso de especialização tinham como característica a abordagem do cuidado em pediatria em todos os níveis de assistência, desde a prevenção à hospitalização, a saber: Programa Integrado de Saúde Materno-Infantil e Familiar (PISMIF-UFRJ); Escola Nacional de Saúde Pública; Creche/Casa de Acolhimento; Centro de Saúde; Ambulatório Pediátrico; Ambulatório de Adolescentes; e Hospital Pediátrico ${ }^{19}$.

Em observância à Resolução do COFEn n ${ }^{0} 100 / 73^{6}$, os cenários de prática do curso atendem aos diferentes setores que compõem a Enfermagem Pediátrica.

Conforme o relatório do curso de especialização, no ano de 1989, o corpo docente era formado por professores da EEAN/UFRJ, professores convidados e profissionais de diversas áreas, sendo estes enfermeiros, médicos, nutricionistas, odontólogos e psicólogos; no entanto, o número de profissionais que possuem apenas graduação é bastante elevado em detrimento aos demais títulos (Tabela 2). Isto se explica pelo fato do número reduzido de cursos de mestrado e doutorado em Enfermagem Pediátrica nos anos de 1980 no país.

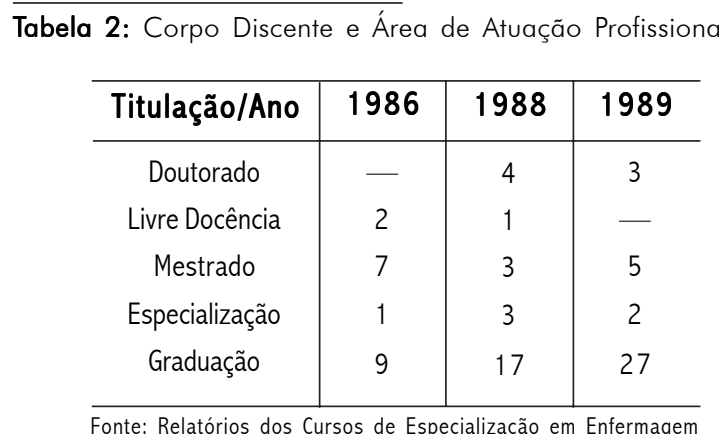

Fonte: Relatórios dos Cursos de Especialização em Enfermagem Pediátrica dos anos de 1986, 1988 e 1989 (DEMI-EEAN/UFRJ).

Até a implantação da Reforma Universitária, em 1968, o número de universidades brasileiras que ofereciam curso de pós-graduação estricto sensu era muito reduzido, e, até então, a maioria dos docentes universitários não tinha formação acadêmica em nível de mestrado e doutorado ${ }^{20}$. 
A autora afirma que a citada reforma previa que o ensino superior deveria ser ministrado nas universidades, sendo indissociável da pesquisa. 0 primeiro curso de pós-graduação em Enfermagem implantado no Brasil foi o curso de mestrado criado em 1972, na EEAN/UFRJ.

Em relação ao corpo discente, o número de estudantes inscritos foi decrescendo no decorrer dos anos, e a área de atuação profissional desses estudantes foi, em sua maioria, a assistência hospitalar, seguida da docência, com exceção do ano de 1986.

No que se refere aos estudantes advindos da assistência, pode-se supor que eles buscaram o curso de especialização na tentativa de ampliar os conhecimentos técnico-científicos na área, ou para obter um título de pós-graduação com vista a referendar a experiência prática de vários anos.

\section{Especialização em Enfermagem Pediátrica: o caso da EEAAC/ UFF}

0 Curso de Especialização em Enfermagem Pediátrica da EEAAC/UFF foi criado em 1986 e apresentava os seguintes objetivos: proporcionar conhecimentos sobre a assistência global à criança sadia e doente; dar conhecimentos sobre métodos de ensino e técnicas pedagógicas com finalidade de melhorar a elaboração, a execução e a avaliação de programas de ensino para assistência à criança sadia e doente; e oferecer conhecimento de metodologia da pesquisa científica com vistas à elaboração de pesquisas em enfermagem ${ }^{22}$.

Alguns objetivos do curso atendiam a política de saúde infantil da época, visto que, em 1984, foi implantado o PAISC já citado anteriormente.

0 curso destinava-se a atender à demanda de enfermeiras docentes e assistenciais da área materno-infantil e também de outras áreas que visavam trabalhar na assistência à criança, atender à demanda de recém-egressos do Curso de Graduação em enfermagem, além de ampliar o número de enfermeiros com qualificação para ingressarem na pós-graduação stricto sensu ${ }^{22}$.

A Tabela 3 mostra a estrutura curricular do curso, em 1986, com as 17 disciplinas e cargas horárias. A estrutura curricular do curso demonstra certa similaridade com o modelo do Curso de especialização em Pediatria e Puericultura (CEPP) do Departamento de Enfermagem da UNIFESP já citado anteriormente.

Em 1990, assume o Presidente Fernando Collor de Mello (1990-1992), cujo o governo é marcado pela adoção explícita da política neoliberal, estabelecendo uma oferta de serviços sociais diferenciada por grupos ${ }^{23}$.

Neste mesmo ano, entra em vigor o Estatuto da Criança do Adolescente (ECA), que incorpora a doutrina sócio-jurídica de proteção integral. 0 governo e a sociedade colocam os direitos da criança e do jovem numa perspectiva condizente com sua condição de pessoa em desenvolvimento e que merecem proteção integral: física, psíquica e moral24.

Em 1991, houve uma reestruturação do curso em relação à estrutura curricular, carga horária e número de créditos. Essa reestruturação ocorreu em virtude de, após a implementação de dois cursos consecutivos e observadas as avaliações de docentes e discentes, os coordenadores do curso
Tabela 3: Estrutura Curricular

\begin{tabular}{|c|c|c|c|}
\hline Disciplinas & 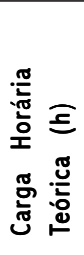 & 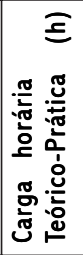 & 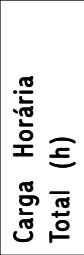 \\
\hline $\begin{array}{l}\text { - Psicologia do } \\
\text { Desenvolvimento }\end{array}$ & 30 & - & 30 \\
\hline - Psicologia Geral & 30 & - & 30 \\
\hline - Psicopedagogia & 30 & - & 30 \\
\hline - Didática & 30 & 30 & 60 \\
\hline $\begin{array}{l}\text { - Metodologia da } \\
\text { Pesquisa Científica }\end{array}$ & 30 & 60 & 90 \\
\hline - Pesquisa Bibliográfica & 15 & - & 15 \\
\hline - Bioestatística & 30 & - & 30 \\
\hline - Sociologia Geral & 15 & - & 15 \\
\hline - Direito Social & 30 & - & 30 \\
\hline - Enfermagem Perinatal & 30 & 60 & 90 \\
\hline - Enfermagem Neonatal & 30 & 60 & 90 \\
\hline - Higiene Infantil & 45 & 60 & 105 \\
\hline $\begin{array}{l}\text { - Enfermagem em } \\
\text { Pediatria Social }\end{array}$ & 30 & 60 & 90 \\
\hline - Nutrição Materno-Infantil & 45 & - & 45 \\
\hline $\begin{array}{l}\text { - Enfermagem Pediátrica } \\
\text { Médica e Cirúrgica }\end{array}$ & 90 & 150 & 240 \\
\hline $\begin{array}{l}\text { - Enfermagem em Doenças } \\
\text { Infecto-Contagiosa }\end{array}$ & 30 & 60 & 90 \\
\hline $\begin{array}{l}\text { - Enfermagem } \\
\text { Otorrinolaringológica } \\
\text { e Oftalmológica }\end{array}$ & 30 & 30 & 60 \\
\hline TOTAL & 570 & 570 & 1140 \\
\hline
\end{tabular}

Fonte: Projeto do Curso de Especialização em Enfermagem Pediátrica, 1986 (CCM/UFF).

terem constatado a necessidade de alterações na estrutura curricular para atender ao corpo discente ${ }^{25}$.

A carga horária total do curso sofreu uma redução de 270 horas, passando de 1.140 para 870 horas, e os créditos reduziram proporcionalmente, de 57 para 39 créditos.

$\mathrm{Na}$ reestruturação do curso ocorreu a exclusão das disciplinas Sociologia Geral, Direito Social e Enfermagem Otorrinolaringológica e Oftalmológica, e, ainda, a disciplina Higiene Infantil passou a ser denominada Saúde da Criança. As disciplinas incluídas foram Semiologia Pediátrica, Unidade de Terapia Intensiva Pediátrica e Monografia.

Apesar da inclusão/exclusão de disciplinas, o curso se manteve similar ao modelo do curso de especialização do Departamento de Enfermagem da UNIFESP. Supõe-se que a reestruturação do curso ocorreu para atender as exigências do mercado de trabalho à época.

Dentro da concepção liberal, a condição de mercadoria da força de trabalho é reforçada, assim como a mercantilização dos bens sociais ${ }^{26}$. Com isto, os profissionais de enfermagem nessa década vivem um momento crítico de desvalorização social expresso pelos baixos salários, condições de trabalho inadequadas, jornadas exaustivas, entre outros ${ }^{27,28}$. 
Quanto ao corpo docente, a Tabela 4 mostra que o número de mestres foi, em todos os anos, maior que as demais titulações. Além disso, destaca-se que houve apenas um docente com título de doutor durante o período de 1986 a 1994, que era professor de bioestatística, conforme foi identificado nos relatórios ${ }^{29}$.

Tabela 4: Corpo Docente e Titulação

\begin{tabular}{c|c|c|c|c|c}
\hline Especificações/Ano & 1986 & 1988 & 1992 & 1994 & 1995 \\
\hline Doutor & 1 & 1 & 1 & 1 & - \\
Livre-Docente & 1 & 2 & 2 & 2 & 2 \\
Mestre & 9 & 8 & 5 & 6 & 8 \\
Especialista & 3 & 3 & 2 & 4 & 2
\end{tabular}

Fonte: Relatórios do Curso de Especialização em Enfermagem Pediátrica (DEMI/EEAAC/ UFF e CCM/UFF).

A primeira turma do curso, em 1986, era constituída por 15 alunas, sendo que dessa turma pioneira apenas 13 concluíram o curso. No ano de 1994, houve apenas 4 alunos inscritos, diferentemente de 1988 e 1992, quando a turma era composta de 11 e 12 alunos, respectivamente.

Vale destacar que não foram encontrados dados referentes aos cenários de prática do curso e também procedência do corpo discente.

\section{A Especialização em Enfermagem Neonatal: o caso da FENF/ UERJ}

0 Curso de Especialização em Enfermagem Neonatal da FENF/UERJ foi criado em 1992. A FENF/UERJ foi a primeira faculdade de enfermagem pública do Estado do Rio de Janeiro a oferecer um curso de especialização em Enfermagem Neonatal. De acordo com a deliberação $n^{0}$ 005/92 o seu compromisso deveria ser atender às necessidades do mercado de trabalho eà qualificação de docentes para o magistério superior.

Neste ano, a iniciativa Hospital Amigo da Criança ganhou impulso no Brasil. Essa proposta foi idealizada, em 1990, pela Organização Mundial de Saúde (OMS) e pelo Fundo das Nações Unidas para a Infância (UNICEF) para promover, proteger e apoiar o aleitamento materno, tendo em vista 0 elevado índice de desmame precoce ${ }^{30}$.

0 Curso de Especialização em Enfermagem Neonatal oferecia, em média, de 12 a 13 disciplinas por ano. Estas disciplinas eram divididas em dois módulos que tiveram várias denominações ao longo dos anos, a saber: $1^{0} \mathrm{e} 2^{0}$ módulo; módulo básico e módulo específico; e disciplinas eletivas e obrigatórias ${ }^{31}$.

A Tabela 5 apresenta a relação das 13 disciplinas, distribuídas em 2 módulos, do primeiro ano do curso, com suas respectivas cargas horárias teórica e prática.

No período de 1993 a 1999, essa estrutura curricular passou por algumas mudanças, ou seja, três disciplinas foram excluídas e duas incluídas. A disciplina Enfermagem Neonatal foi excluída no período de 1993-1994, mas voltou a fazer parte da estrutura curricular no ano seguinte. As outras duas disciplinas excluídas foram: Estágio Sistematização da Assistência de Enfermagem e Enfermagem Neonatal e seu âmbito de ação. Em 1997, foi incluída a disciplina Dinâmica de Relacionamento Interpessoal ${ }^{31}$.
Tabela 5: Disciplinas e Carga Horária

\begin{tabular}{|c|c|c|}
\hline \multirow{2}{*}{ Disciplinas $1^{\circ}$ Módulo } & \multicolumn{2}{|c|}{ Carga Horária } \\
\hline & teórica & prática \\
\hline 1.Teorias de Administração & 30 & - \\
\hline $\begin{array}{l}\text { 2. Pedagogia das } \\
\text { Ciências da Saúde }\end{array}$ & 60 & - \\
\hline $\begin{array}{l}\text { 3. Metodologia Científica na } \\
\text { Resolução de Problemas }\end{array}$ & 15 & 30 \\
\hline 4. Política de Saúde & 30 & - \\
\hline $\begin{array}{l}\text { 5. Tópicos de Filosofia } \\
\text { Contemporânea }\end{array}$ & 30 & - \\
\hline $\begin{array}{l}\text { 6. Sistematização da } \\
\text { Assistência de Enfermagem }\end{array}$ & 30 & - \\
\hline $\begin{array}{l}\text { 7. Ciências Sociais, Humanas } \\
\text { e o Exercício da Enfermagem }\end{array}$ & 30 & - \\
\hline $\begin{array}{l}\text { 8. Contradições e Dilemas } \\
\text { da Profissão }\end{array}$ & 15 & - \\
\hline $\begin{array}{l}\text { 9. Estágio: Sistematização } \\
\text { da Assistência de Enfermagem }\end{array}$ & - & 45 \\
\hline \multicolumn{3}{|l|}{ Disciplinas $2^{\circ}$ Módulo } \\
\hline $\begin{array}{l}\text { 10. Enfermagem Neonatal } \\
\text { e seu âmbito de ação }\end{array}$ & 45 & - \\
\hline 11. Enfermagem Neonatal & 75 & - \\
\hline $\begin{array}{l}\text { 12. Investigação Científica } \\
\text { na Enfermagem Neonatal }\end{array}$ & 30 & - \\
\hline $\begin{array}{l}\text { 13. Estágio Supervisionado } \\
\text { em Enfermagem Neonatal }\end{array}$ & - & 360 \\
\hline \multirow{2}{*}{ Total } & 390 & 450 \\
\hline & \multicolumn{2}{|c|}{825} \\
\hline
\end{tabular}

Fonte: Relatório do Curso de Especialização em Enfermagem Neonatal, 1992. (Centro de Memória-FENF/UERJ).

No contexto governamental, com o impeachment do presidente Fernando Collor de Mello, em 1992, Itamar Franco assume o governo, permanecendo até 1994. Em janeiro de 1995, Fernando Henrique Cardoso (1195-2002) assume a presidência, sendo um governo caracterizado por privatizações e reformas. 0 programa do governo foi pautado em aumento e garantia dos recursos públicos para a saúde, expansão e consolidação do Sistema Único de Saúde e melhora da qualidade da atenção $0^{23}$.

Vale assimilar que, em 1996, houve um número elevado de óbitos de recém-nascidos em diversos hospitais do país, a saber: 30 mortos em São Luis - Maranhão; 11 em Niterói - Rio de Janeiro; 51 em Fortaleza - Ceará, entre outros ${ }^{17}$.

Quanto aos cenários de prática, a disciplina Estágio Supervisionado em Enfermagem Neonatal era realizada em parceria com uma maternidade da rede municipal (no ano de 1992/93) e um hospital pediátrico da rede federal (no ano de 1992/1993 e 1993/94). Em ambos, o setor de treinamento era o berçário. No entanto, na maternidade, os alunos passavam pela admissão, intermediário e alto risco, e no hospital pediátrico, passavam pela admissão, intermediário, UTINeonatal e alojamento conjunto ${ }^{31}$.

Supõe-se que a escolha dos cenários de prática do início do curso tenha tido como critério instituições de referência do 
Ministério da Saúde, como consta no Projeto Pedagógico do Curso de Especialização em Enfermagem Neonatal ${ }^{32}$.

A carga horária total e o número total de créditos das disciplinas do curso sofreram alterações no decorrer do período. Destaca-se que de 1992 até 1997, a carga horária era de 825 horas, e no ano de 1999 esta carga horária se reduziu para 360 horas.

Vale destacar que a carga horária total do curso apresentou um decréscimo em dois momentos, foram eles a reestruturação (1997) e a reformulação do curso (1999). Estas alterações carga horária total/créditos ocorreram com base nas deliberaç̃̃es da UERJ já citadas anteriormente.

Em 1995-1996 ocorreu uma redução do número de créditos, pois a disciplina Pedagogia das Ciências passou de 3 para 2 créditos, e em 1996-1997 voltou a ter 3 créditos. Em 1999 a redução do número de créditos foi proporcional à redução da carga horária ${ }^{31}$.

Pode-se dizer que no período de 1992 a 1999, o curso atendeu as exigências de a Resolução n ${ }^{0} 12 / 83$ do Ministério da Educação no que se refere à carga horária mínima de 360 horas.

Em relação ao corpo docente e sua titulação, a Tabela 6 mostra que o número de docentes com título de mestre foi, em todos os anos, maior ou igual a todas as outras titulações, exceto 1996/97 e 1999, dos quais não há registro nos citados relatórios.

Tabela 6: Corpo Docente do Curso e Titulação

\begin{tabular}{c|c|c|c|c|c}
\hline \multirow{2}{*}{ Ano do curso } & \multicolumn{5}{|c}{ Titulação } \\
\cline { 2 - 6 } & Doutores & $\begin{array}{c}\text { Livre- } \\
\text { docentes }\end{array}$ & Mestres & Especialistas & Total \\
\hline $1992-1993$ & 4 & 6 & 7 & 2 & 19 \\
$1993-1994$ & 8 & 6 & 11 & 1 & 26 \\
$1994-1995$ & 7 & 4 & 7 & 1 & 19 \\
$1995-1996$ & 5 & 2 & 7 & 1 & 15 \\
$1996-1997$ & - & - & - & - & - \\
1997 & 4 & 1 & 4 & 0 & 10 \\
1998 & 5 & 1 & 7 & 0 & 13 \\
1999 & - & - & - & - & - \\
\hline
\end{tabular}

Fonte: Relatórios do Curso de Especialização em Enfermagem Neonatal (Centro de Memória-FENF/UERJ).

0 quantitativo de docentes com título de especialista foi sempre menor que $1 / 3$ do total de docentes, estando, portanto, em conformidade com as exigências da Resolução n ${ }^{0}$ 12/83.

Em relação ao corpo discente, o número de alunos esteve de acordo com o número mínimo estabelecido para funcionamento do curso nas deliberações da UERJ. De acordo com os relatórios, o número de alunos formados, na sua maioria, era menor do que o número dos matriculados, que se mantinha o mesmo. Estas desistências ocorreram por motivo de licença maternidade, transferência para outro curso de especialização ou por abandono do curso. Isso representou um percentual médio de desistência em todo o período igual a $15 \%$.

Desses alunos, a maioria era residente na cidade do Rio de Janeiro e trabalhou/trabalhava em hospitais gerais e em hospitais pediátricos. Alguns alunos tiveram experiência em maternidades. No período de 1994-1995, não há registro da experiência profissional dos alunos no relatório, e, em 1999, também faltam dados da procedência dos alunos.

\section{CONSIDERAÇÕES FINAIS}

0 Curso de Extensão Universitária em Enfermagem Pediátrica da EEAN/UFRJ, criado em 1974, foi a gênese para a criação do curso de especialização. Em 1983, o curso passou para o nível de aperfeiçoamento e, então, após 12 anos, foi denominado Curso de Especialização em Enfermagem Pediátrica.

0 Curso de Especialização em Enfermagem Pediátrica da EEAAC/UFF foi criado em 1986 nos moldes do curso promovido pelo Departamento de Enfermagem da UNIFESP, pioneiro na implantação da especialidade no país, em 1972.

0 Curso de Especialização em Enfermagem Neonatal da FENF/UERJ foi criado em 1992 para atender a demanda do mercado de trabalho e a qualificação dos docentes do ensino superior.

Verifica-se que os cursos atendiam as exigências do CFE e as legislações (resoluções e deliberações) específicas de cada universidade.

Com base na caracterização dos cursos de especialização em Enfermagem Pediátrica e Neonatal, constata-se que os mesmos apresentavam disciplinas que abordavam a criança e o recém-nascido nos aspectos curativo e preventivo.

Constatou-se que os cursos apresentavam diferenças entre si, visto que um dos cursos era específico de Enfermagem Neonatal e os outros dois eram de Pediatria. Além disso, os cursos de pediatria também eram diferentes entre si, já que o da EEAN/UFRJ e FENF/UERJ punha em destaque a criança no cenário hospitalar, e o da EEAAC, a criança na comunidade.

Os cenários da prática dos cursos (EEAN/UFRJ e FENF/ UERJ) estavam voltados para os diferentes níveis de assistência e especificidades de cada faixa etária (recémnascido até adolescente).

0 corpo docente dos cursos era formado por professores com titulação de mestrado e doutorado. Em relação aos professores de Enfermagem, constatou-se que as referidas titulações predominaram no final dos anos de 1980, visto que era reduzido o número de cursos de mestrado e doutorado nessa década no país.

De modo geral, o quantitativo do corpo discente foi reduzindo ao longo dos anos. No caso da FENF/UERJ, a redução foi ocasionada por diferentes motivos (licença maternidade, transferência para outro curso de especialização ou por abandono do curso).

Conclui-se que a criação e a implementação dos três cursos demarcam a institucionalização da especialidade Enfermagem Pediátrica no Estado do Rio de Janeiro. 


\section{Referências}

1. Oliveira ICS. (Re)construindo a assistência de enfermagem à criança hospitalizada na cidade do Rio de Janeiro: 1920-1969. [tese de doutorado]. Rio de Janeiro (RJ): Escola de Enfermagem Anna Nery / UFRJ; 1996.

2. Ferriani MGC, Rocha SMM, Cano MAT. A prática da enfermagem pediátrica no Estado de São Paulo. Anais do $37^{\circ}$ Congresso Brasileiro de Enfermagem; 1985; Recife (PE), Brasil. Recife (PE): ABEn; 1985. p. 371-81.

3. Barbosa VL. Os paradigmas do curso de especialização em Enfermagem Neonatológica. Acta Paulista Enferm 1996; (9): 33-6.

4. Vieira MPDA, et al. A pesquisa em história. São Paulo (SP): Ática; 1989. 5. Lüdke M, André MEDA. Pesquisa em educação: abordagens qualitativas. São Paulo (SP): EPU; 1986.

6. Santos EF, et al. Legislação em enfermagem: atos normativos do exercício e do ensino de enfermagem. São Paulo (SP): Atheneu; 2002.

7. Resolução n¹4/77, de 23 de novembro de 1977. Fixa condições de validade dos certificados dos cursos de aperfeiçoamento e especialização para o magistério superior. Documenta 1977 dez; 205.

8. Universidade Federal do Rio de Janeiro. Resolução CPEG $n^{\circ} 78$. Regulamenta os cursos em nível de aperfeiçoamento, especialização, treinamento profissional e atualização. Boletim UFRJ 1978 nov; 30( 48).

9. Resolução $n^{0} 12 / 83$ de 6 de outubro de 1983. Fixa novas condições para validade dos certificados dos cursos de Aperfeiçoamento e Especialização. Documenta, 1983 nov; 275

10. Universidade Federal Fluminense. Resolução $n^{\circ}$ 25/81. Boletim de Serviço 1981 maio; 85.

11. Universidade Federal do Rio de Janeiro. Escola de Enfermagem Anna Nery. Coordenação dos Cursos de Pós-Graduação da EEAN. Regulamento dos Cursos de Pós-Graduação em Enfermagem Lato-sensu;1989.

12.Universidade Federal Fluminense. Decisão n 153/91. Aprova nova estrutura do curso de especialização em Enfermagem Pediátrica da Escola de Enfermagem Aurora Afonso Costa. Boletim de Serviço1991 nov 4; 161.

13. Universidade do Estado do Rio de Janeiro. Deliberação nº 05/92. Autoriza a criação do curso de especialização em Enfermagem Neonatal da Faculdade de Enfermagem da UERJ. Rio de Janeiro (RJ): Centro de Memória; 1992

14 . Deliberação nº 022/97. Autoriza a reestruturação do curso de especialização em enfermagem neonatal da Faculdade de Enfermagem da UERJ. Rio de Janeiro (RJ): Centro de Memória; 1997

15. Ministério de Educação (BR). Conselho Nacional de Educação. Resolução CES ño 3 de 7 de outubro de 1999. Dispõe sobre os cursos de especialização e dá outras providências. Diário Oficial da República Federativa do Brasil, Brasília (DF), 1999. Seção 1:52.

16. Universidade do Estado do Rio de Janeiro. Deliberação n027/99. Autoriza a reformulação do curso de especialização em Enfermagem Neonatal da Faculdade de Enfermagem da UERJ. Rio de Janeiro (RJ): Centro de Memória; 1999

17. Neves GP, et al. História do Brasil: de "terra ignota" ao Brasil atual. Rio de Janeiro (RJ): Log0n; 2002.

18. Ministério da Saúde (BR). Programa de Assistência Integral à Saúde da Criança, 1984. Brasília (DF). Disponível em: www.saude.gov.br/prog

19. Universidade Federal do Rio de Janeiro. Escola de Enfermagem Anna Nery. Relatórios do curso de especialização em Enfermagem Pediátrica. Departamento de Enfermagem Materno- Infantil: 1986/1988/1989.

20. Baptista SS. Trajetória das escolas de enfermagem na sociedade brasileira. Escola Anna Nery Rev Enferm 1997 dez.; 1 (2): 84-105.
21. Ministério da Saúde (BR) Programa de Saúde do Adolescente. Brasília (DF); 1989. Disponível em: www.saude.gov.br/prog

22. Universidade Federal Fluminense. Centro de Ciências Médicas. Projeto do curso de especialização em Enfermagem Pediátrica, Rio de Janeiro (RJ): Centro de Ciências Médicas; 1986

23. Fonseca RMG S, Forcella HT, Bertolozzi M R. Congressos Brasileiros de Enfermagem; meio século de compromisso da ABEn. Brasilia(DF): ABEn; 2000. 24. Lei $n^{0} 8069$ de 13 de julho de 1990. Dispõe sobre o Estatuto da Criança e do Adolescente e dá outras providências. Brasilia(DF): Ministério da Saúde; 1991.

25. Universidade Federal Fluminense. Centro de Ciências Médicas. Projeto de reestruturação do curso de especialização em Enfermagem Pediátrica. Rio de Janeiro: Centro de Ciências Médicas; 1991

26. Bertolozzi MR, Greco R M. As políticas de saúde no Brasil: reconstrução histórica e perspectivas atuais. Rev Esc Enferm USP 1996 dez; 30 (3): 380-98.

27. Barros SMPF. Discurso da Presidente da ABEn Nacional-Sessão de abertura. In: Anais do $42^{\circ}$ Congresso Brasileiro de Enfermagem; 1990; Natal(RN), Brasil. Natal(RN): ABEn Seção RN; 1990. p.29-31.

28. Fonseca RMGS. Atenção: mulheres trabalhando: na vida, na saúde, na enfermagem. In: Fonseca, RMGS et al. Mulher e cidadania na nova ordem social. São Paulo(SP): NEMGE;1996.

29. Universidade Federal Fluminense. Escola de Enfermagem Aurora Afonso Costa. Relatórios do curso de especialização em enfermagem pediátrica. Departamento de Enfermagem Materno-Infantil e Psiquiatria: 1986/1988/ 1992/1994/1995.

30. Universidade Estadual do Estado do Rio de Janeiro. Faculdade de Enfermagem. Relatórios do curso de especialização em enfermagem neonatal. Rio de Janeiro (RJ): Centro de Memória; 1992-1999.

31. Fundo das Nações Unidas para a Infância. Iniciativa Amigo da Criança. Disponível em www.unicef.org/brazil

32. Universidade do Estado do Rio de Janeiro. Faculdade de Enfermagem. Projeto Pedagógico do curso de especialização em Enfermagem Neonatal. Rio de Janeiro (RJ); s/d.

\section{Sobre as Autoras}

\section{Jakcilane Rosendo de Gois}

Graduanda do $8^{\circ}$ período do Curso de Graduação em Enfermagem e Obstetrícia da Escola de Enfermagem Anna Nery da Universidade Federal do Rio de Janeiro. Bolsista de Iniciação Científica/CNPq.

\section{Priscila dos Anjos Fonseca}

Graduanda do $8^{\circ}$ período do Curso de Graduação em Enfermagem e Obstetrícia da Escola de Enfermagem Anna Nery da Universidade Federal do Rio de Janeiro. Bolsista de Iniciação Científica/ FAPERJ.

\section{Suzy Groeger Lapa}

Graduanda do $8^{\circ}$ período do Curso de Graduação em Enfermagem e Obstetrícia da Escola de Enfermagem Anna Nery da Universidade Federal do Rio de Janeiro. Bolsista de Iniciação Científica/ FAPERJ.

\section{Isabel Cristina dos Santos Oliveira}

Doutora em Enfermagem, Professora Adjunta do Departamento de Enfermagem Médico-Cirúrgica da EEAN/UFRJ. Orientadora. Líder do Grupo de Pesquisa - Saúde da Criança/ Cenário Hospitalar. Pesquisadora CNPq. 